\title{
EDUARDO LOURENÇO LEITOR de Vergílio Ferreira
}

\section{Eduardo Lourenço: Vergílio Ferreira reader}

\author{
Marcelo Franz
}

\begin{abstract}
RESUMO
Inspirado na leitura da trajetória de Eduardo Lourenço, por ocasião de seu nonagésimo aniversário, este estudo busca situar possíveis relações entre seu pensar e o de Vergílio Ferreira, seu contemporâneo e amigo, falecido em 1996. Analisaremos os modos como, ao longo de décadas, Lourenço lê Vergílio Ferreira, percebendo como o olhar de Lourenço na direção da ficção e da ensaística vergilianas revela algo dos métodos e ênfases temáticas de sua discussão sobre literatura e filosofia, bem como seu posicionamento no espectro ideológico de Portugal no século XX. O mais importante ponto de aproximação dos dois autores é o conceito de "heterodoxia" desenvolvido por Lourenço. Esse conceito também pode ser entendido como o norte da opção estética assumida por Vergílio Ferreira a partir do fim dos anos 1940.
\end{abstract}

Palavras-chave: Eduardo Lourenço; Vergílio Ferreira; heterodoxia.

* PUCPR. 


\begin{abstract}
Inspired by the trajectory of Eduardo Lourenço, on the occasion of his ninetieth birthday, this study seeks to situate possible relationships between his thinking and the thinking of Vergílio Ferreira, his contemporary friend, who died in 1996. We analyze the ways in which, over decades, Lourenço read Vergílio Ferreira, noticing how the look of Lourenço in the direction of Vergílio Ferreira's fictions and essays reveals something of the methods and thematic emphases of his discussion about literature and philosophy, as well as its position on the ideological spectrum of Portugal in the twentieth century. The most important point, in which both authors get closer, is the concept of "heterodoxy", developed by Lourenço. This concept can also be understood as the center of the aesthetic choice assumed by Virgil Ferreira from the late 1940s on.
\end{abstract}

Keywords: Eduardo Lourenço; Vergílio Ferreira; heterodoxy.

\title{
1. Considerações INICIAIS
}

É certo que a percepção do valor das amizades, por si só, é insuficiente para se constatar troca de influências entre intelectuais. A própria noção de amizade é imprecisa quando se trata da interação de ideias e criações do espírito, que nem sempre depende de intensa convivência. Todavia, em muitos casos, pode-se tomar a aproximação entre dois pensadores como um fator a se considerar na compreensão das particularidades de ambos.

A reflexão a que nos propomos se baseia no levantamento de alguns dos pronunciamentos de Eduardo Lourenço sobre Vergílio Ferreira, a fim de se recompor, no que for possível, o perfil do romancista de acordo com o amigo filósofo. Com efeito, foram (ou talvez ainda venham sendo) muitos os julgamentos de Lourenço sobre Vergílio Ferreira publicados em variados espaços, antes e depois da morte deste em 1996. Buscaremos nessa aproximação verificar os modos como, ao longo de décadas, Lourenço lê Vergílio Ferreira. Uma problemática que nos atrai é a percepção de que o olhar de Lourenço na direção de Vergílio Ferreira revela muito do seu pensar ou do seu agir filosófico. Os seus julgamentos a respeito da ficção e da ensaística 
vergilianas podem ser valiosos para que, por meio deles, se deslinde algo dos métodos e ênfases temáticas do pensar de Lourenço sobre literatura e filosofia, bem como de seu posicionamento no espectro ideológico de Portugal no século XX.

Não se pode inferir da recolha de suas opiniões, considerando a gama de autores analisados por Lourenço em sua produção crítica, nenhuma "preferência" ou prioridade conferida ao estudo da criação vergiliana - lembremos, entre tantas, das suas alentadas leituras sobre Miguel Torga, Raul Brandão e Fernando Pessoa. Contudo, a observação do "caso" Vergílio Ferreira sempre lhe mereceu uma atenção especial, a ponto de se poder deduzir que Lourenço vê nos usos estéticos e nas reflexões filosóficas deste autor uma confluência de tendências, assumidas e rechaçadas, incorporadas e combatidas, que sintetizam - não raro de modo crítico -, no seu contexto histórico, algumas das faces mais complexas da literatura moderna de Portugal. $\mathrm{Na}$ contrapartida, Vergílio Ferreira, em seu modo contido, manifestou-se sobre Lourenço considerando-o seu melhor crítico ${ }^{1}$.

Sendo isentas, as análises do estudioso evitam colocar a obra vergiliana num patamar hierárquico elevado ou "influente" sobre o que se lhe seguiria; mas, de modo geral, apontam Vergílio Ferreira como um criador-emblema dos embates da criação do século XX com seu entorno nas esferas estética, ética e ideológica. Em 2004, em reportagem do Correio da Manhãa, de Lisboa, Lourenço declarou sobre Vergílio:

Tinha com Vergílio Ferreira uma relação de longa amizade, iniciada nos anos 50 e que durou até à sua morte. Do homem, retenho a seriedade com que encarava o mundo e a exigência para com tudo o que o cercava, até para com os amigos a quem ouvia tanto quanto julgava. Não era um homem fácil e muito menos tranquilo. (LOURENÇO, apud GUSMÃO, 2004).

Essa proximidade tem como cenário de início a agitação cultural dos fins dos anos 1940, período de conturbação e incertezas, no qual a ação pensante dos dois jovens intelectuais dialoga, de modo amplo, com um contexto de inevitável militância, marcado pela polarização e pela radicalidade. 


\section{Lourenço Heterodoxo}

A afirmação da personalidade intelectual de Eduardo Lourenço se dá a ver de modo mais definido a partir de 1949. Antes disso, no início de sua trajetória de professor em Coimbra, Lourenço colaborou em revistas onde, além de ter tentado alguma poesia, publicou uma série de ensaios que nesse ano seriam reunidos sob o titulo de Heterodoxia I, numa primeira edição de autor. Caberia contextualizar o nascedouro desses textos em periódicos ligados ao ambiente acadêmico de Coimbra, muitos deles, como a revista Vértice, meios de difusão do pensamento de esquerda e da então emergente literatura neorrealista. A sua inquietação, assumida desde então como heterodoxa, paradoxalmente tem como um dos alvos de sua crítica, embora não de modo exclusivo, a estreiteza e o sectarismo do ambiente intelectual da esquerda em que atuava.

o panorama de pensamento que marcou essa geração é afetado em sua base pelo trauma da segunda guerra mundial, a instabilidade do pós-guerra e as urgências da reconstrução. Para os portugueses, igualmente traumática é a experiência do obscurantismo da ditadura do Estado Novo - que impunha pobreza cultural e censura aos pensadores. É difícil conceber, no fragor da luta de resistência contra o totalitarismo, um intelectual que não se mostrasse suscetível ao discurso de crítica das desigualdades e arbitrariedades dos poderosos daqueles dias, fosse no país, fosse fora dele.

Em Portugal, a ação idiotizante do Salazarismo sobre o povo mais simples parecia potencializada pela cooptação, por parte das forças de repressão e propaganda do governo, do discurso religioso mais conservador, alvo incontornável do pensar e do agir crítico de Lourenço nesse tempo ${ }^{2}$. 0 mundo vivia o rescaldo da hecatombe militar e da crise de valores a asso-

2 Um exemplo da ação dirigida do governo sobre as mentalidades da população portuguesa na época é a forma como o Estado Novo se vale da propaganda para seus intentos. Em comemoração aos dez anos de governo de Salazar, em 1938 é lançada e distribuída nas escolas primárias uma série de sete cartazes intitulada A Lição de Salazar. A intenção é disseminar valores por parte do Estado Novo, destinando-se a glorificar a obra do ditador na economia e nas obras públicas. Segundo Felipa Cruz Azevedo, o que se retrata nessas Lições: "É o mundo perfeito, sem violência, sem vícios, sem protestos, perfeitamente ordenado, traduzindo uma ordem económica, política e social que o Estado Novo considerava perfeitas. A escola é o palco privilegiado para a inculcação dos valores defendidos pelo Estado Novo. Os manuais escolares, livros únicos para o então Ensino Primário, criteriosamente seleccionados pelo Ministério da Educação Nacional e adoptados por longos anos, dão-nos imensos exemplos desses valores: a glorificação da obra do Estado Novo e do seu líder, Salazar; o papel subalterno da mulher, limitada à função de esposa e mãe; a caridade que, quantas vezes, substitui a função social do Estado; a catequese, incutindo os rudimentos da doutrina católica; a gloriosa história pátria que transforma Portugal na Nação mais bela do mundo e de que o Estado Novo é o mais legítimo herdeiro" . (A LIÇÃo DE SALAZAR. Disponível em: < https://sites.google.com/ site/filipacruzazevedo/home >. Acesso em: 8 nov. 2014.) 
ciada. O movimento operário e os partidos de esquerda - assumidos como a vanguarda ideológica em países da Europa ocidental, mas já tutelados à distância pelo Comunismo soviético - sustentavam que havia um mundo a salvar, um futuro a construir. A alternativa à esquerda parecia, para aquela geração, a mais razoável no plano político, bem como a escrita engajada e crítica do neorrealismo parecia a expressão estética mais plausível em face desse projeto de salvação.

Há que se reparar, entretanto, que sendo hegemônica, a adesão ao pensamento de esquerda (ou ao daquela esquerda e seus emblemas) é bastante matizada e relativizável, e o processo de revisão, crítica e afastamento dos bons princípios assumidos por alguns de seus entusiastas da primeira hora se mostra, em muitos casos, um caminho inevitável. Em meados dos anos 1940, já é possível perceber uma boa quantidade de ex-adeptos do receituário nacional-popular, uns tantos que já estavam na viagem de retorno da utopia - ou, ao menos, da utopia que antes se havia proposto, nos termos como nela se chegou a acreditar em contextos mais passionais. As razões para isso serão variadas e idiossincráticas demais para que se trace um quadro geral. Sabe-se, contudo, que é notável nesse período a crescente crítica ao método do centralismo democrático imposto pelas alas diretivas e decisórias do "movimento", entendido por alguns como um fator de sufocação das individualidades. Igualmente, denuncia-se a burocratização das relações no interior dos partidos socialista e comunista - clandestinos e atuantes de modo heroico nos espaços possíveis dos ambientes intelectual e artístico. Alie-se a isso a percepção difusa de umas tantas carências conceituais na formulação das propostas de construção do propalado e aguardado "futuro".

A rigor, é no que tange às questões conceituais, corolário do empenho pensante a ser, nos termos de Heidegger, assumido por todo intelectual, que Lourenço se indispõe com as simplificações bem intencionadas do movimento ao qual se ligou. Em que pese o fato de a situação política em Portugal ensejar ou justificar a busca por uma ruptura frontalmente decidida, o vínculo tutelar com o Comunismo soviético era antevisto por alguns - entre os quais o jovem Lourenço - como pouco inspirador, já que, ainda que abafados, chegavam rumores das mais tarde conhecidíssimas arbitrariedades impostas aos opositores pelo regime stalinista. Como acreditar na construção de um mundo novo tendo por modelo algo que, no plano da ação repressora, era tão obscurantista quanto o que se combatia na frente doméstica?

A participação de Lourenço nesse contexto o leva à assunção de um combate às ortodoxias dominantes, tanto à direita (amparada no discurso oficial respaldado pela filosofia da Igreja conservadora do período anterior ao Concílio Vaticano II) quanto à esquerda (difundida hegemonicamente entre os intelectuais pelo discurso da resistência, sustentada pelo Mar- 
xismo dogmático). A transgressão aos dogmatismos cobra o seu preço em contextos de polarização. $O$ fato é que, sem transigir em face do caminho pelo qual optou, o pensamento de Lourenço aguardaria o melhor momento para se fazer compreender para além dos preconceitos ou do absolutismo dos que propõem verdades gerais entrincheirados num dos polos do eterno maniqueísmo que simula opor "reacionários" a "revolucionários".

A heterodoxia se constitui como uma espécie de impressão digital de seu pensamento, embora a conceituação precisa do pensar e do agir heterodoxos não seja singular. Ser heterodoxo é, em grande medida, assumir a instabilidade dos conceitos e da verdade. É essa postura que o leva a mesmo por vezes à distância, na condição de emigrado, antes e depois de 25 de Abril de 1974 - jamais ter abdicado de uma função pensante ativa, notável na série de pronunciamentos sobre a realidade cultural e política de Portugal, em ensaios contundentes e corajosos, debatendo a condição ou o "destino" do país nas suas relações com a Europa, sobretudo na voga das transformações por que passou o continente nas décadas anteriores. O fato é que em suas reflexões é marca dominante o equilíbrio entre a erudição - que faz remissão ao pensar sobre o passado e a história, com vistas e elucidar os enigmas do presente - e a expressão de uma personalidade inconformista e, em suma, pouco afeita a simplificações classificatórias.

Em muitos momentos, e quase sempre sem um planejamento dos dois, Lourenço terá uma consciência intelectual irmanada à de Vergílio Ferreira, a seu modo também um heterodoxo.

\section{A Heterodoxia de Vergílio Ferreira}

Se não fosse um reducionismo indesejável, seria tentador afirmar que a compreensão global da obra de Vergílio Ferreira por Lourenço aponta para uma espécie de reconhecimento - constatado, sutilmente exaltado e em muitos casos aspirado - da obra e do pensar de um nos de outro, dada a identificação em pontos de suas trajetórias, marcadas a princípio, e de modo comungado, pela leitura e compreensão que fazem do momento histórico dos anos 1940, não obstante as opções por encaminhamentos particulares em cada caso - Vergílio Ferreira se definindo como ficcionista e (ou "enquanto"?) ensaísta e Eduardo Lourenço mais propriamente como filósofo ligado à academia. Tocados igualmente pela intenção de combate ao Estado Novo e cientes - como, de resto, a sua geração - de que deveriam intervir na realidade política e social daqueles dias, a princípio, por força do magnetismo ideológico então em voga, os dois se posicionaram de modo inevitável à esquerda. Assim como Lourenço, Vergílio, que só o conheceria 
depois, teve textos publicados na Vértice e cortejou a arte neorrealista em seus primeiros livros, que seriam, de certo modo, rejeitados por ele mais tarde. Pode-se observar que a construção das identidades autorais dos dois é marcada pelo confronto mais ou menos áspero com o receituário ideológico que se vivenciava nos âmbitos da esquerda em Portugal naqueles anos. É essa intenção de ruptura que, por um lado, os aproxima e, por outro, os marginaliza com relação à intelectualidade de seu tempo.

Já nos anos 1980, Vergílio Ferreira definiria, em retrospectiva, sua fase inicial neorrealista nos seguintes termos:

Eu entrei no neorrealismo, ou seja, na arte social, como quem entra para o convento, quer dizer pela abdicação. Recordo o meu primeiro livro e por entre o seu doloroso infantilismo, reconheço agora que o que então já me preocupava era outra coisa (...). Do interesse "coletivo» (referido preferentemente a uma problemática socioeconómica) não passei para um interesse "individual», mas, para, digamos, um "coletivo» de outra ordem: o "homem". (FERREIRA, 1981, p.100)

Em 1949, Eduardo Lourenço escreve o prefácio da primeira edição do romance Mudança. Trata-se do primeiro texto crítico a buscar de modo consistente a compreensão da obra de Vergílio Ferreira, elucidando-a a partir da evolução dos procedimentos e temas do autor desde sua estreia em 1943 com O caminho Fica Longe - ainda apegado de modo crédulo aos esquematismos neorrealistas - até a incursão pelo universo da indagação existencialista que marcará, a partir de então, a sua identidade criativa, crescentemente automarginalizada no quadro das correntes de pensamento dominantes no cenário intelectual português da segunda metade do século $\mathrm{XX}$. Acrescente-se que o texto de Lourenço tem, também, um traço algo inaugural, definindo um modo de interpretação pelo qual os estudiosos vergilianistas se deixarão influenciar. 0 crítico observa que:

Mudança - título profético como todos os que convêm à hora que designa, - é um livro que abre caminho através da sua própria construção, caminho que é ruptura ou, em todo o caso, desconfiança em relação à luz excessivamente clara que banhava então o nosso universo romanesco. Ele abriu as portas do seu autor para paragens cada vez mais desoladas e exaltantes. (LOURENÇO, 1969, pp. IX-X).

$\mathrm{Na}$ base do estudo de Lourenço nesse prefácio está pressuposta a aproximação dos dois em torno da preocupação com a condição humana para além do problema das condições sócio-históricas determinantes na 
ação das personagens. $O$ anseio universalizante da reflexão que subjaz a esse julgamento situa o drama humano numa esfera à parte das condições de classe. $O$ centro nervoso da opção feita pela ficção de Vergílio Ferreira - e referendada pelo pensar de Eduardo Lourenço - parece a indagação incessante, construída por um discurso literário que a informe. Nas obras e no pensar de ambos, de um modo não isento de crises, importava, nas palavras de Vergílio, "salvar o invencível sonho do homem".

Sem deixar de sublinhar o intenso humanismo atuante - e não apenas contemplativo - da ficção de Vergílio ao longo do tempo, a leitura crítica da sua obra feita por Eduardo Lourenço acentua que "o estatuto do eu" ligado ao "primado da subjetividade" aparece como uma "intensa dramatização" na encenação homem-mundo, que se constrói no corpo da narrativa e no ato narrativo entendido como elevação. $O$ dizer e a força da palavra, tema obsessivo dos romances-problema de Vergílio Ferreira, é sentido e esperado como "aparição" e instante em que o "eu" das personagens se encontra consigo mesmo. Contudo, sendo o dizer um ato voltado também "ao outro", acontece igualmente o encontro do eu com o mundo. Segundo Lourenço, no ensaio Vergílio Ferreira: Do Alarme à Jubilação, esse encontro é feito de espanto e "deslumbramento, pânico, revelação de um sentido de verdade, enfim, tudo o que o escritor entende como indeterminação no mundo e mistério". (LOURENÇO, 1986, p. 26). Por outro lado, o crítico acentua que a "jubilação", nos romances de Vergílio Ferreira, parece ter por fundamento um estado de profunda "alegria breve" enquanto representa o instante do encontro da palavra esperada.

Mesmo praticando diferentes formas de escrita ${ }^{3}$, o pensar existencialista é, por certo, o motivo maior de aproximação entre os dois pensadores por volta da metade do século XX. Em ambos, o Existencialismo traduz-se como a expressão de um espírito de interrogação e angústia, pondo em questão valores religiosos, sociais, ideológicos, fundamentos da existência humana e tendo como pano de fundo o trauma da segunda guerra mundial e os desafios da reconstrução (no que fosse possível) do mundo - com sua insegurança - no pós-guerra.

3 O ensaísmo de Vergílio Ferreira, praticado desde os anos 1950, tem títulos que podem ser considerados clássicos da escrita filosófica em Portugal no século XX. Citemos, entre tantos, Carta ao Futuro (1958), Invocação ao Meu Corpo (1969) e Pensar (1992). Contudo, o próprio autor se entendia mais que tudo como um romancista que buscava um trânsito dentro do espaço da filosofia pela prática do livre pensar. Sua aproximação aos casos de Albert Camus e Jean-Paul Sartre, igualmente romancistas e filósofos, confirma uma tendência de época, que é a da quebra de barreiras entre os discursos da literatura e da filosofia. 
Em passagem de $O$ Canto do Signo, mapeando a prolífera produção de ideias da metade do século XX, Lourenço pondera a respeito de Vergílio Ferreira e do que denomina a "geração da utopia":

Como não evocar as sombras tutelares de Malraux e Camus? Em poucas obras portuguesas tais presenças são hoje mais visíveis. Alguns críticos falam a seu respeito de 'existencialismo'. Se se quiser: Outras o merecem menos. Em todo caso, tal referência tem valor de signo. Quem não sabe que nada foi mais violentamente atacado pelo realismo progressista do que a espécie 'existencialista' que agora se refere sem embaraços na garganta e até com secreta cumplicidade? Meandros da dialética, senão do conformismo cultural puro e simples. (LOURENÇO, 1994, p. 44)

Como se percebe em Heterodoxia, Lourenço entenderá, em sua própria criação filosófica - percebendo vínculos com o que propõe Vergílio - a existência como instância fugidia a qualquer justificação racional. Os primados da contingência e da facticidade também estão pressupostos, assim como a ampla recusa das soluções fora da esfera da concretude da vida, o que o afasta de qualquer crença religiosa. A percepção do desamparo existencial advém da precariedade ontológica do humano diante do que the supera. Nos dois autores persiste, em tons particulares em cada caso-e com mais intensidade na fase em que Lourenço afirma sua heterodoxia - uma visão trágica e dilemática do homem que, ao mesmo tempo, se abre ao que Vergílio Ferreira definirá, em seu romance mais renomado, como "aparição", entendida como possibilidade de esclarecimento do mistério dos aparentes despropósitos do existir. Em passagem do romance de 1959, o narrador Alberto - definido por Lourenço como um alter-ego de Vergílio - diz:

Pela primeira vez eu tinha o alarme dessa viva realidade que era eu, desse ser vivo que até então vivera comigo na absoluta indiferença de apenas ser e em que agora descobrira qualquer coisa mais que me excedia e me metia medo. Quantas vezes mais tarde eu repetiria a experiência no desejo de fixar essa aparição fulminante de mim a mim próprio, essa entidade misteriosa que eu era e agora absolutamente se me anunciava. (FERREIRA, 1988 p. 63)

Cabe acrescentar que Lourenço, em seus estudos de Vergílio Ferreira, é um dos críticos que melhor definem a distinção advogada pelo ficcionista entre dois tipos de romance: o romance-espetáculo e o romance-problema, também chamado "romance-ensaio", cuja característica maior é a densidade da reflexão. Defendendo este último e invocando a sua pertinência, num 
contexto de necessário esforço pensante por parte do artista, Vergílio concebe o romance como espaço de indagação - por vezes desnorteante e em detrimento da fluidez do enredo, buscando como objetivo fundamental enunciar um problema, ainda que não procure - ou não acredite em - "soluções".

\section{Heterodoxia E InTEMPoralidade}

Pela leitura da dimensão existencialista de suas criações podemos aproximar intelectualmente os dois autores cuja amizade mútua se manteve durante longo tempo. Em seu ensaio publicado no livro-homenagem In Memoriam de Vergílio Ferreira, Eduardo Lourenço pondera sobre a atualidade da arte e do pensamento do autor, definindo-o como:

alguém para quem a inscrição no tempo, a obsessão com o tempo foi permanente, nisso de acordo com a coerência mesma da ficção moderna. Curiosamente, essa obsessão pelo tempo é, por assim dizer, acompanhada da obsessão mais radical do "intemporal", porque a intuição central da sua visão do mundo é que o essencial escapa, por isso mesmo, a toda a sua inscrição o espaço, mas também no tempo, não apenas porque é da ordem do intemporal, no sentido de que tem uma existência realmente fora do tempo, mas porque, aquém do tempo ou para além do tempo, há essa realidade sem nome da qual nós fazemos parte, que nós somos e que é em nós. (LOURENÇO apud JÚLIO, 2003)

Lourenço observa que o tempo - na incerta e jamais conclusiva reflexão que sobre ele se pudesse fazer - é o principal eixo temático no transcurso da escrita de Vergílio Ferreira. Embora com modulações, ele é reincidente e constituinte da identidade artística e ensaística do autor. A princípio, seu olhar crítico se volta às complexidades de um tempo preciso e às projeções para além dele (por exemplo, a ideia de "futuro") que surgiam desse "zeitgeist". Lourenço observa que:

Vergílio Ferreira não tem como horizonte na sua reflexão esse passado eterno, mas tem, e escreve, em função de uma espécie de tempo que seria um tempo no qual os homens enfim estariam face a face com o mistério enfim resolvido da sua vida: quer dizer, uma espécie de futuro utópico, ou o futuro como utopia. Esse texto, como sabemos, é a Carta ao Futuro, de 1957, um texto que - confesso - não relia há muito e que subtrai um pouco à mitologia pessoal de Vergílio Ferreira, enquanto romancista de um tempo que está fora do tempo, o tempo imemorial da Origem, inscrevendo-a efetivamente num dado momento de nosso tempo contemporâneo de uma maneira bem precisa. Num momento em 
que a questão do futuro não era uma questão neutra, mas era a questão de uma utopia proposta aos homens, aos da sua geração, na qual as contradições humanas, o espetáculo da alienação que constitui a própria história humana e sobretudo aquela que era representada pela sociedade burguesa então em crise, ou assim parecia, decide Vergílio Ferreira, decide Vergílio Ferreira endereçar ao futuro sua famosa carta, na qual praticamente todos os tópicos da sua visão das coisas já estão presentes. A ficção futura irá dar um corpo ficcional àquilo que aqui é uma mistura entre o conceptual e o ficcional. (LOURENÇO apud JÚLIO, 2003).

Lourenço compreende a inevitável fusão do ficcional e do filosófico em Vergílio Ferreira como um caminho para a expressão de um pensar profundo sobre o tempo. Contudo, embora se contextualize nas coordenadas de uma época e a ela faça remissão, é ao tempo em sua dimensão ontológica que a criação vergiliana se volta.

Igualmente, a filosofia de Eduardo Lourenço revela uma preocupação com questões humanas gerais que superam o limitado de circunstâncias históricas, embora com elas dialoguem. Há, portanto, muitos pontos de contato entre a reflexão de Vergílio sobre o tempo e o pensamento de Lourenço sobre o ser humano em qualquer tempo. A postura de ambos diante dos problemas do seu país e do mundo transcende limitações temporais ou coordenadas ideológicas na medida em que problematiza, com ou sem o rótulo (nem sempre suficiente) de "existencialista", as certezas ou doutrinas estabelecidas sobre a definição do humano e sua condição. A ficção e o ensaísmo de Vergílio Ferreira, assim como a filosofia e a crítica literária de Eduardo Lourenço, buscam uma resposta aos embates de muitos ou de todos os tempos, tendo um sentido de humanismo que lhes garante vigor e relevância. 
FranZ, M. Eduardo Lourenço leitor de Vergílio Ferreira

\section{REFERÊNCIAS}

FERREIRA, Vergílio. Mudança. 3. ed. Lisboa: Portugália Editora, 1969. . Um Escritor Apresenta-se. Lisboa: Imprensa Nacional - Casa da Moeda, 1981. . Aparição. 5. ed. Lisboa: Bertrand, 1988.

GUSMÃO, Dina. "Recordar Vergílio Ferreira”. Correio da Manhã, Lisboa, 9 mar. 2004.

JÚLIO, Maria Joaquina Nobre (Org.). In Memoriam de Vergílio Ferreira. Lisboa: Bertrand Editora, 2003.

LOURENÇO, Eduardo. “Àcerca de Mudança”. In: FERREIRA, Vergílio. Mudança. 3. ed. Lisboa: Portugália Editora, 1969.

. Vergílio Ferreira: do alarme à jubilação. Colóquio - Letras, n. 90, 1986.

. Heterodoxia. Lisboa: Assírio \& Alvim, 1987;

.Vergílio Ferreira e a Geração da Utopia”. In: O Canto do Signo - Existência e Literatura (1957-1993). Lisboa: Editoral Presença, 1994.

A LIÇÃo DE SALAZAR. Disponível em: <https://sites.google.com/site/filipacruzazevedo/home>. Acesso em: 8 nov. 2014.

Submetido em: 11/04/2014

Aceito em: 31/10/2014 